\title{
New Fourth Order Iterative Methods Second Derivative Free
}

\author{
Osama Y. Ababneh \\ Department of Mathematics, Zarqa University, Zarqa, Jordan \\ Email: osababneh@zu.edu.jo
}

Received 23 February 2016; accepted 20 March 2016; published 23 March 2016

Copyright (C 2016 by author and Scientific Research Publishing Inc.

This work is licensed under the Creative Commons Attribution International License (CC BY). http://creativecommons.org/licenses/by/4.0/

c) (i) Open Access

\begin{abstract}
In a recent paper, Noor and Khan [M. Aslam Noor, \& W. A. Khan, (2012) New Iterative Methods for Solving Nonlinear Equation by Using Homotopy Perturbation Method, Applied Mathematics and Computation, 219, 3565-3574], suggested a fourth-order method for solving nonlinear equations. Per iteration in this method requires two evaluations of the function and two of its first derivatives; therefore, the efficiency index is $\mathbf{1 . 4 1 4 2 1}$ as Newton's method. In this paper, we modified this method and obtained a family of iterative methods for appropriate and suitable choice of the parameter. It should be noted that per iteration for the new methods requires two evaluations of the function and one evaluation of its first derivatives, so its efficiency index equals to 1.5874 . Analysis of convergence shows that the methods are fourth-order. Several numerical examples are given to illustrate the performance of the presented methods.
\end{abstract}

\section{Keywords}

Newton's Method, Fourth-Order Convergence, Third-Order Convergence, Non-Linear Equations, Root-Finding, Iterative Method

\section{Introduction}

In this paper, we consider iterative methods to find a simple root of a nonlinear equation $f(x)=0$, where $f: D \in R \rightarrow R$ for an open interval $D$ is a scalar function. The classical Newton's method is given by

$$
x_{n+1}=x_{n}-\frac{f\left(x_{n}\right)}{f^{\prime}\left(x_{n}\right)}, n=0,1,2, \cdots
$$

This is an important and basic method [1], which converges quadratically. Recently, Noor [2] proposed a new fourth-order method defined by 


$$
x_{n+1}=y_{n}-\frac{f\left(y_{n}\right)}{f^{\prime}\left(x_{n}\right)}-\left(\frac{f\left(y_{n}\right)}{f^{\prime}\left(x_{n}\right)}\right)\left(1-\frac{f^{\prime}\left(y_{n}\right)}{f^{\prime}\left(x_{n}\right)}\right)-\frac{1}{2}\left(\frac{f\left(y_{n}\right)}{f^{\prime}\left(x_{n}\right)}\right)^{2} \frac{f^{\prime \prime}\left(y_{n}\right)}{f^{\prime}\left(x_{n}\right)},
$$

where $y_{n}=x_{n}-f\left(x_{n}\right) / f^{\prime}\left(x_{n}\right)$.

It is clear that to implement (2), one has to evaluate the second derivative of the function. This can create some problems. In order to overcome this drawback, several techniques have been developed [3]-[6]. In [7], a second-derivative-free method is obtained through approximating the second derivative $f^{\prime \prime}\left(y_{n}\right)$ in (3) by

$$
f^{\prime \prime}\left(y_{n}\right) \cong \frac{f^{\prime}\left(y_{n}\right)-f^{\prime}\left(x_{n}\right)}{y_{n}-x_{n}} .
$$

In a recent paper, Noor and Khan [8] have used the same approximation of the second derivative (3) in (2) to suggest the following Iterative methods

$$
x_{n+1}=y_{n}-\frac{2 f\left(y_{n}\right)}{f^{\prime}\left(x_{n}\right)}+\left(\frac{f\left(y_{n}\right) f^{\prime}\left(y_{n}\right)}{f^{\prime 2}\left(x_{n}\right)}\right)+\left(\frac{f^{\prime}\left(y_{n}\right)-f^{\prime}\left(x_{n}\right)}{2 f\left(x_{n}\right)}\right)\left(\frac{f\left(y_{n}\right)}{f^{\prime}\left(x_{n}\right)}\right)^{2} .
$$

In this paper, we rederive the method in (4) to obtain a family of fourth-order method free from second derivative. Moreover, per iteration in these new methods requires two evaluations of the function and just one of its first derivatives.

The rest of this paper is organized as follows. The proposed methods are described in Section 2. In Section 3, the convergence analysis is carried out to establish the order of convergence. Finally, in Section 4, the methods are tested on some numerical examples and comparisons of the results of our methods.

\section{Description of the Methods}

The following approximations of $f^{\prime}\left(y_{n}\right)$ are obtained in [9]

$$
\begin{aligned}
& f^{\prime}\left(y_{n}\right) \approx \frac{f^{\prime}\left(x_{n}\right) f\left(x_{n}\right)^{2}}{f\left(x_{n}\right)^{2}+2 f\left(x_{n}\right) f\left(y_{n}\right)+f\left(y_{n}\right)^{2}}, \\
& f^{\prime}\left(y_{n}\right) \approx \frac{f^{\prime}\left(x_{n}\right)\left(f\left(x_{n}\right)+f\left(y_{n}\right)(\beta-2)\right)}{f\left(x_{n}\right)+\beta f\left(y_{n}\right)},
\end{aligned}
$$

where $\beta \in R$. We then apply the approximations (5) and (6) to the method (4). Now, Combining (5) and (4), we get the new iterative method

$$
\begin{aligned}
x_{n+1}= & y_{n}-\left(\frac{2 f\left(y_{n}\right)}{f^{\prime}\left(x_{n}\right)}\right)+\left(\frac{f\left(x_{n}\right)^{2} f\left(y_{n}\right)}{f^{\prime}\left(x_{n}\right)\left(f\left(x_{n}\right)+f\left(y_{n}\right)\right)^{2}}\right) \\
& +\left(-\frac{f\left(y_{n}\right) f^{\prime}\left(x_{n}\right)\left(2 f\left(x_{n}\right)+f\left(y_{n}\right)\right)}{2 f\left(x_{n}\right)\left(f\left(x_{n}\right)+f\left(y_{n}\right)\right)^{2}}\right)\left(\frac{f\left(y_{n}\right)}{f^{\prime}\left(x_{n}\right)}\right)^{2} .
\end{aligned}
$$

Using (6) in (4), we get a new family of iterative method

$$
\begin{aligned}
x_{n+1}= & y_{n}-\left(\frac{2 f\left(y_{n}\right)}{f^{\prime}\left(x_{n}\right)}\right)+\left(\frac{f\left(y_{n}\right)\left(f\left(x_{n}\right)+f\left(y_{n}\right)(\beta-2)\right)}{f^{\prime}\left(x_{n}\right)\left(f\left(x_{n}\right)+\beta f\left(y_{n}\right)\right)}\right) \\
& +\left(-\frac{f^{\prime}\left(x_{n}\right) f\left(y_{n}\right)}{f\left(x_{n}\right)\left(f\left(x_{n}\right)+\beta f\left(y_{n}\right)\right)}\right)\left(\frac{f\left(y_{n}\right)}{f^{\prime}\left(x_{n}\right)}\right)^{2} .
\end{aligned}
$$

Essentially, we consider the convergence criteria of the new methods in (7) and (8), and this is the main motivation of our next result. 


\section{The Analysis of Convergence}

Theorem 1. Let $\alpha \in I$ be a simple zero of sufficiently differentiable function $f: I \rightarrow R$ for an open interval I. If $x_{0}$ is sufficiently close to $\alpha$, where $e_{n}=x_{n}-\alpha$ and $c_{k}=f^{(k)}(\alpha) / k$ !. Then the methods defined by (7) and (8) are of fourth-order convergence and satisfy the error equations

$$
e_{n+1}=\left(7 c_{2}^{3}-c_{2} c_{3}\right) e^{4}+O\left(e^{5}\right),
$$

and

$$
e_{n+1}=\left(c_{2}\left(5 c_{2}^{2}+2 \beta c_{2}^{2}-c_{3}\right)\right) e^{4}+O\left(e^{5}\right), \forall \beta \in R
$$

Proof.

Using Taylor expansion of $f\left(x_{n}\right)$ about $\alpha$ and taking into account that $f^{\prime}(\alpha) \neq 0$, we have

$$
f\left(x_{n}\right)=f^{\prime}(\alpha)\left[e_{n}+c_{2} e_{n}^{2}+c_{3} e_{n}^{3}+c_{4} e_{n}^{4}+O\left(e_{n}^{5}\right)\right] .
$$

Furthermore, we have

$$
f^{\prime}\left(x_{n}\right)=f^{\prime}(\alpha)\left[1+2 c_{2} e_{n}+3 c_{3} e_{n}^{2}+4 c_{4} e_{n}^{3}+O\left(e_{n}^{4}\right)\right],
$$

and

$$
\frac{f\left(x_{n}\right)}{f^{\prime}\left(x_{n}\right)}=e_{n}-c_{2} e_{n}^{2}+2\left(c_{2}^{2}-c_{3}\right) e_{n}^{3}+\left(7 c_{2} c_{3}-4 c_{2}^{3}-3 c_{4}\right) e_{n}^{4}+O\left(e_{n}^{5}\right) .
$$

Substituting (11) in $y_{n}=x_{n}-\frac{f\left(x_{n}\right)}{f^{\prime}\left(x_{n}\right)}$ yields

$$
y_{n}-\alpha=c_{2} e_{n}^{2}-2\left(c_{2}^{2}-c_{3}\right) e_{n}^{3}-\left(7 c_{2} c_{3}-4 c_{2}^{3}-3 c_{4}\right) e_{n}^{4}+O\left(e_{n}^{5}\right) .
$$

Expanding $f\left(y_{n}\right)$ about $\alpha$ and using (12), we have

$$
f\left(y_{n}\right)=f^{\prime}(\alpha)\left[c_{2} e_{n}^{2}-2\left(c_{2}^{2}-c_{3}\right) e_{n}^{3}-\left(7 c_{2} c_{3}-4 c_{2}^{3}-3 c_{4}\right) e_{n}^{4}+O\left(e_{n}^{5}\right)\right] .
$$

Using Equations (9)-(13) in method (7) we have the following error equation:

$$
e_{n+1}=\left(7 c_{2}^{3}-c_{2} c_{3}\right) e^{4}+O\left(e^{5}\right),
$$

this means that the method defined by (7) is fourth order. Also, using Equations (9)-(13) in (8) we get the following error equation:

$$
e_{n+1}=\left(c_{2}\left(5 c_{2}^{2}+2 \beta c_{2}^{2}-c_{3}\right)\right) e^{4}+O\left(e^{5}\right),
$$

which means that the family defined by (8) is of order four $\forall \beta \in R$.

This completes the proof of the theorem.

If we consider the definition of efficiency index as $p^{\frac{1}{w}}$, where $p$ is the order of the method and $w$ is the number of function evaluations per iteration required by the method, then the fourth-order method (4) has the efficiency index equal to $\sqrt[4]{4} \approx 1.41421$, while for the newfourth order methods (7) and (8) is $\sqrt[3]{4} \approx 1.5874$ which is better than method defined by (4).

\section{Numerical Results}

All computations were done using the Mathematica package using 64 digit floating point arithmetic's. We accept an approximate solution rather than the exact root, depending on the precision $(\epsilon)$ of the computer. We use the following stopping criteria for computer programs: $\left|x_{n+1}-x_{n}\right| \prec \varepsilon$ and so, when the stopping criterion is satisfied, $x_{n+1}$ is taken as the exact root $\alpha$ computed. We used the fixed stopping criterion $\epsilon=10^{-15}$.

It is well-known that the convergence of iteration formula is guaranteed only when the initial approximation is sufficiently near to root. In general, it may be divergent when initial approximation is far from the root. 
We employ the present methods to solve some nonlinear equations, which not only illustrate the methods practically but also serve to check the validity of theoretical results we have derived, the following

$$
\begin{aligned}
& f_{1}(x)=x^{3}+4 x^{2}-10, \alpha=1.3652300134140968457608068290, \\
& f_{2}(x)=\sin ^{2} x-x^{2}+1, \alpha=1.404491648215341, \\
& f_{3}(x)=x^{2}-\mathrm{e}^{x}-3 x+2, \alpha=0.2575302854398608, \\
& f_{4}(x)=\cos x-x, \alpha=0.73908513321516064165531208767, \\
& f_{5}(x)=(x-1)^{3}-2, \alpha=2.22599210498948731647672106073, \\
& f_{6}(x)=x \mathrm{e}^{x^{2}}-\sin ^{2} x+3 \cos x+5, \alpha=-1.207647827130919, \\
& f_{7}(x)=(x+2) \mathrm{e}^{x}-1, \alpha=-0.44285440100238858314132800000, \\
& f_{8}(x)=\mathrm{e}^{\left(x^{2}+7 x-30\right)}-1, \alpha=3 .
\end{aligned}
$$

Displayed in Table 1 the number of iterations to approximate the zero $(\mathrm{N})$ and the number of function evaluations (TNFE) counted as the sum of the number of evaluations of the function itself plus the number of evaluations of the derivative. We present some numerical test results for various iterative schemes in Table 1.

\begin{tabular}{|c|c|c|c|c|c|c|c|c|c|c|}
\hline & \multicolumn{5}{|c|}{$\mathrm{N}$} & \multicolumn{5}{|c|}{ TNFE } \\
\hline & NM & NOR & MNR1 & MNR2 & MNR3 & NM & NOR & MNR1 & MNR2 & MNR3 \\
\hline$f_{1}, x_{0}=1.0$ & 5 & 3 & 3 & 3 & 3 & 10 & 12 & 9 & 9 & 9 \\
\hline$f_{1}, x_{0}=-0.3$ & 53 & 38 & 22 & 56 & 17 & 106 & 152 & 66 & 168 & 51 \\
\hline$f_{2}, x_{0}=2.0$ & 5 & 3 & 3 & 4 & 3 & 10 & 12 & 9 & 12 & 9 \\
\hline$f_{2}, x_{0}=3.0$ & 6 & 3 & 4 & 4 & 4 & 12 & 12 & 12 & 12 & 12 \\
\hline$f_{3}, x_{0}=1.0$ & 4 & 2 & 2 & 2 & 2 & 8 & 8 & 6 & 6 & 6 \\
\hline$f_{3}, x_{0}=2.0$ & 5 & 3 & 3 & 3 & 3 & 10 & 12 & 9 & 9 & 9 \\
\hline$f_{4}, x_{0}=1.0$ & 4 & 2 & 2 & 2 & 2 & 8 & 8 & 6 & 6 & 6 \\
\hline$f_{4}, x_{0}=1.7$ & 4 & 3 & 3 & 3 & 3 & 8 & 12 & 9 & 9 & 9 \\
\hline$f_{5}, x_{0}=0.0$ & $\mathrm{NC}$ & 4 & 3 & 4 & 3 & - & 16 & 9 & 12 & 9 \\
\hline$f_{5}, x_{0}=-1.0$ & 12 & 5 & 6 & 5 & 6 & 24 & 20 & 18 & 15 & 18 \\
\hline$f_{6}, x_{0}=-1.0$ & 5 & 3 & 4 & 3 & 4 & 10 & 12 & 12 & 9 & 12 \\
\hline$f_{6}, x_{0}=-2.0$ & 8 & 5 & 5 & 5 & 5 & 16 & 20 & 15 & 15 & 15 \\
\hline$f_{7}, x_{0}=2.0$ & 8 & 5 & 5 & 5 & 5 & 16 & 20 & 15 & 15 & 15 \\
\hline$f_{7}, x_{0}=-5.0$ & 4 & 2 & 2 & 2 & 2 & 8 & 8 & 6 & 6 & 6 \\
\hline$f_{8}, x_{0}=3.5$ & 12 & 7 & 7 & 7 & 7 & 24 & 28 & 21 & 21 & 21 \\
\hline$f_{8}, x_{0}=4.0$ & 19 & 11 & 12 & 11 & 12 & 38 & 44 & 36 & 33 & 36 \\
\hline
\end{tabular}

Compared with the Newton method (NM), the method in (4) (NOR), the new methods in (7) (MNR1), and as an example of (8) we take $\beta=0$ (MNR2), and $\beta=1$ (MNR3). The test results in Table 1 show that for most of the functions we tested. Note that we used NC in Table 1 to mean that the method does not converge to the root. The new methods introduced in the present presentation have at least equal performance compared to the method in (4), and better than Newton method. As far as the results we consider, the new fourth-order methods, require the less NFEs as compared to the Newton's method and method in (4).

Table 1. Comparison of various fourth order schemes and Newton's method. 
As a conclusion, we can infer that the present method has better performance in accordance with the theoretical analysis of the order. However, it should be noted that per iteration the methods (MNR1), (MNR2) and (MNR32) do require two evaluations of the function and one of its first derivative, whereas the method (4) does require two evaluations of the function and two of its first derivative, costing more expensive computation. Thus, the present methods can be of practical interest.

\section{Conclusions}

We have proposed new fourth order methods of iterative methods for solving nonlinear equations. Numerical results show that the number of iterations of the new method is always less than that of the classical Newton's method and the method in (4).

Analysis of convergence of methods is supplied in Theorem 2. Analysis of efficiency shows that these methods are preferable to Newton's method and the fourth order method in (4). The number of function evaluations of the new methods is comparable.

\section{Acknowledgements}

This research is funded by the Deanship of Research in Zarqa University/Jordan.

\section{References}

[1] Ostrowski, A.M. (1973) Solution of Equations in Eucilidean and Banach Space. 3rd Edition, Academic Press, New York.

[2] Noor, M.A. (2010) Some Iterative Methods for Solving Nonlinear Equations Using Homotopy Perturbation Method. International Journal of Computer Mathematics, 87, 141-149. http://dx.doi.org/10.1080/00207160801969513

[3] Chun, C. (2007) Some Third-Order Families of Iterative Methods for Solving Non-Linear Equations. Applied Mathematics and Computation, 188, 924-933. http://dx.doi.org/10.1016/j.amc.2006.10.043

[4] Ezquerro, J.A.M. and Hernandez, A.A. (2003) Uniparametric Halley-Type Iteration with Free Second Derivative. International Journal of Pure and Applied Mathematics, 6, 103-114.

[5] Kou, J.S., Li, Y.T. and Wang, X.H. (2006) A Uniparametric Chebyshev-Type Method Free from Second Derivatives. Applied Mathematics and Computation, 179, 296-300. http://dx.doi.org/10.1016/j.amc.2005.11.110

[6] Kou, J.S., Li, Y.T. and Wang, X.H. (2006) Modified Halleys Method Free from Second Derivative. Applied Mathematics and Computation, 183, 704-708. http://dx.doi.org/10.1016/j.amc.2006.05.097

[7] Noor, M.A. and Gupta, V. (2007) Modified Householder Iterative Method Free from Second Derivatives for Nonlinear Equations. Applied Mathematics and Computation, 190, 1701-1706. http://dx.doi.org/10.1016/j.amc.2007.02.056

[8] Noor, M.A. and Khan, W.A. (2012) New Iterative Methods for Solving Nonlinear Equation by Using Homotopy Perturbation Method. Applied Mathematics and Computation, 219, 3565-3574. http://dx.doi.org/10.1016/j.amc.2012.09.040

[9] Ham, C.Y. (2008) Some Fourth-Order Modifications of Newtons Method. Applied Mathematics and Computation, 197, 654-658. http://dx.doi.org/10.1016/j.amc.2007.08.003 